\title{
Homo erectus in Salkhit, Mongolia?
}

Sang-Hee Lee

Department of Anthropology, University of California at Riverside, Riverside, California 92521-0418, USA

Received 14 September 2014, accepted 5 February 2015

Tel.: +1-951-827-4390. E-mail address: shlee@ucr.edu 


\begin{abstract}
In 2006, a skullcap was discovered in Salkhit, Mongolia. The Salkhit skullcap has a mostly complete frontal, two partially complete parietals, and nasals. No chronometric dating has been published yet, and suggested dates range from early Middle Pleistocene to terminal Late Pleistocene. While no chronometric date has been published, the presence of archaic features has led to a potential affiliation with archaic hominin species. If it is indeed Homo erectus or archaic Homo sapiens, Salkhit implies a much earlier spread of hominins farther north and inland Asia than previously thought. In this paper, the nature of the archaic features in Salkhit is investigated. The Salkhit skullcap morphology and metrics were compared with Middle and Late Pleistocene hominin fossils from northeast Asia: Zhoukoudian Locality 1, Dali, and Zhoukoudian Upper Cave. Results show an interesting pattern: on one hand, the archaic features that Salkhit shares with the Zhoukoudian Locality 1 sample also are shared with other later hominins; on the other hand, Salkhit is different from the Middle Pleistocene materials in the same way later hominins differ from the Middle Pleistocene sample, in having a broader frontal and thinner supraorbital region. This may reflect encephalization and gracilization, a modernization trend found in many places. It is concluded that the archaic features observed in Salkhit are regionally predominant features rather than diagnostic features of an archaic species.
\end{abstract}

\title{
Introduction
}

In 2006, a skullcap was found in Salkhit, Mongolia (48 16'17.9" N, 112²1'37.9" E), by a mining company that was developing the region for a resort, and was brought to the attention of the Mongolian Academy of Sciences (Tseveendorj et al., 2006). The skullcap has a mostly complete frontal, two partially complete parietals, and nasals. Noticing the archaic morphology of the skullcap, Tseveendorj and colleagues reported the find as a new genus, Mongolanthropus, and suggested $800 \mathrm{ka}$ as a possible date based on a woolly rhinoceros discovered in the vicinity (Tseveendorj et al., 2006). The woolly rhinoceros remains, however, were not found together with the hominin fossil, and therefore it is uncertain that they are contemporaneous with the fossil. Furthermore, woolly rhinoceros 
has a lengthy tenure of appearance throughout Pleistocene (Boeskorov, 2012) that the presence of the fossil species alone is not a reliable nor accurate biostratigraphic marker of time. As such, the suggested date of $800 \mathrm{ka}$ is not substantiated, and the various dates that have been suggested range from early Middle Pleistocene (Bae, 2010; Tseveendorj et al., 2006) to terminal Late Pleistocene (Kaifu and Fujita, 2012).

Although unlikely to be as old as $800 \mathrm{ka}$, it is still possible that the fossil is from Middle Pleistocene. Hominin activity has left evidence from late Early Pleistocene in what is now mainland Asia continent (Zhu et al., 2003, 2008) and south Asia (Pappu et al., 2011). Northern extension of hominin activity in Asia has been evidenced by research in the Nihewan basin (Zhu et al., 2001, 2004). Early hominin activity has been documented in Europe as well, showing that hominins spread as far North as $40-45^{\circ} \mathrm{N}$ around $1 \mathrm{Ma}$ ago, dispersing into northern Europe up to $50^{\circ} \mathrm{N}$ around $500 \mathrm{ka}$ (Dennell, 2003). In northeast Asia, the archaeological sites in Nihewan basin such as Majuangou and Xiaochangliang have yielded dates as old as 1.66 Ma for stone-tool use (Ao et al., 2013; Zhu et al., 2001, 2004). Paleolithic sites in the Nihewan basin $\left(40^{\circ} \mathrm{N}, 114^{\circ} \mathrm{E}\right)$ are geographically close to Salkhit, and thus raise a possibility of antiquity for the Salkhit specimen as well.

In the absence of chronometric dating, the skullcap has been associated with a wide range of fossil hominins based on its morphology. Coppens et al. (2008) used a multidimensional scaling method to analyze the mixture of archaic and modern features, and concluded that the Salkhit skullcap clusters with Neandertals, Homo erectus, archaic Homo sapiens, but ruled out modern Homo sapiens. Coppens and colleagues's study focused on the possible affinity between Salkhit and the Neandertals. If so, it would increase the Neandertal distribution further east of Okladnikov Cave, currently known to be the east-most Neandertal site (Bae, 2010; Derevianko, 2011). However, no research has examined explicitly the possibility that Salkhit is a Homo erectus: Coppens et al. (2008) did not eliminate Homo erectus as a possible affiliation.

It is well-documented in paleoanthropology that archaic features appear in archaic specimens as well as later specimens that present a mixture of archaic and modern features (Wolpoff, 1999). These alternatives raise a central question of this paper: does Salkhit look archaic because it is an archaic specimen or because it has archaic ancestors? 
I compare Salkhit skullcap with the Middle and Late Pleistocene specimens of geographic vicinity: Zhoukoudian sample, both the Locality 1 and the Upper Cave, and Dali (Fig. 1). Jinniushan, another hominin specimen from northeast Asia, was not included in this study because of the unavailability of a cast.

\section{INSERT Fig. 1 ABOUT HERE}

\section{Morphological Comparison}

Because only the skullcap is preserved, limited morphological and metric comparisons were possible. Close attention was paid to the supraorbital region, which gives the specimen an archaic appearance. Observation and measurements for the Salkhit skullcap were made on the original specimen as well as on a cast. Photographs are from the original specimen. Comparisons with other specimens were done with casts only.

The Salkhit skullcap consists of a mostly complete frontal, partially preserved parietals of both sides, and partially preserved nasals of both sides. The external surface of the bone has scratch marks from erosion. The internal surface of the bone does not have scratch marks. Both external and internal surfaces have stains of unknown source (Figs. 2 and 3).

\section{INSERT Fig. 2 AND Fig. 3 ABOUT HERE}

Sutures are closed. Ectocranially, a weak coronal suture can be seen with some difficulty, and it is even more difficult to observe the coronal suture endocranially. The coronal suture can be observed as a weak line, with the slightest denticulation that can be identified under light and by touch. The sagittal suture is more visible than the coronal suture, as the suture is closed but not fused completely, although it is obliterated at bregma. The crenulations are visible both endocranially and ectocranially.

Since an ectocranial suture is better for age assessment than an endocranial suture (Meindl and Lovejoy, 1985), and sagittal suture closure is not a sensitive marker of age (Hershkovitz et al., 1997), the coronal suture being ectocranially obliterated gives support 
for an assessment of the individual being of a mature age at death. However, it is impossible to have an age assessment beyond that it was an adult (Buikstra and Ubelaker, 1994; Figure 22b) even it could be assumed that the same standards of age assessment developed from modern humans can be applied with comparable accuracy. Based on general gracility (except for the supraorbital torus), it might be a female; however, the supraorbital region is robust, and other cranial regions that may show robustness are not

preserved, such as the temporals and the occipital bone. Furthermore, robusticity by itself is not a reliable diagnostic basis for sex assessment without a population-specific reference sample (Weiss, 1972). There is no way to ascertain the age and sex of the specimen, solely based on morphology.

Since it is difficult to identify homologous points for comparison of different specimens (Marsh, 2013), thickness at bregma was compared. Salkhit cranial thickness at bregma $(6 \mathrm{~mm})$ is thinner than the Zhoukoudian range $(7-10.6 \mathrm{~mm})$. No thickness data were available for the Upper Cave specimens.

\section{Frontal}

The frontal includes the squama and supraorbital torus, and the orbital roof is preserved with the breadth of $13 \mathrm{~mm}-17 \mathrm{~mm}$ along the length of the supraorbital torus. However, inferior edges of the frontal are missing, except for the lateral edge of the supraorbital torus including the frontozygomatic suture. The temporal fossa portion of the frontal preserves an inferior edge that is broken but runs in parallel to the temporal ridge on both sides.

The coronal suture is not complete, extending $80 \mathrm{~mm}$ to the right of bregma, and 60 $\mathrm{mm}$ to the left of bregma. Maximum distance from the temporal line toward the temporal bone is $24 \mathrm{~mm}$ on the right, and $14 \mathrm{~mm}$ on the left. Coronal suture on the right side extends infero-laterally past the temporal line, for $16.4 \mathrm{~mm}$. On the left side, coronal suture stops at the temporal line, and the bone is broken off. The coronal suture is not preserved posterior to the end of the supraorbital torus, and there is no frontosphenoid suture.

Although the correct orientation following the Frankfurt Horizontal is uncertain, an approximate orientation can be estimated based on the supraorbital and the nasal 
morphology. The forehead seems low but it is not flat (Fig. 4). It rises almost vertically from the supraorbitals to the metopion (highest point above the nasion-bregma line), which is at about anterior 1/3 point of the line connecting nasion and bregma. Superior to the metopion the forehead continues the arc that flattens out.

\section{INSERT Fig. 4 ABOUT HERE}

A weak sagittal keel is present on the frontal (Fig. 5). The keel begins to rise about 22 $\mathrm{mm}$ postero-superiorly to glabella. The keel continues postero-superiorly for about 72 $\mathrm{mm}$ on the frontal, then it becomes low and flat about $30 \mathrm{~mm}$ anterior to bregma. There is no prebregmatic eminence. Salkhit shares similarity with the Zhoukoudian sample in having a sagittal keel on the frontal; however, it is not as prominent as in the Zhoukoudian sample, most prominently expressed in Zhoukoudian XII. The sagittal keel on the frontal is also observed in Dali and UC 101. Salkhit and UC 101 have comparably weak sagittal keel on the frontal.

\section{INSERT Fig. 5 ABOUT HERE}

The anterior portion of the temporal ridges has a distinct angulation to the bone inferior to them. However, about $44 \mathrm{~mm}$ posterior from the anterior edge of the supraorbital torus, the ridge becomes less prominent and gradually weakens as it crosses the coronal suture (Fig. 4). This is clearly seen on the right side, and the left side is not seen easily because the bone is broken off. The left temporal fossa has a slight flare at the inferior end of the temporal fossa that is remaining.

On the internal surface of the frontal, frontal crest is developed, rising from the point that corresponds to metopion ectocranially (Fig. 3). The frontal crest meets the internal surface of the frontal, then it immediately divides into two lips to allow for sagittal sinus. Weidenreich considers this a "modern condition" (Weidenreich, 1951:250-251).

The maximum height of the frontal crest, ectocranially corresponding to glabella, is 9 $\mathrm{mm}$. The frontal crest measures $42.7 \mathrm{~mm}$ in length. The lips of the sulcus continue for 17 
$\mathrm{mm}$ then disappear, and do not reach the coronal suture. Several pacchionian pits are observed along the mid-sagittal plane.

In frontal length, Salkhit is within the range of the Zhoukoudian sample (Table 1); so are Dali and Upper Cave specimens. The groups do not show differences in frontal length, in either arc or chord measurements. The frontal curvature index (=(arc/chord)*100) of Salkhit (109.12) is larger than the Zhoukoudian values but smaller than that of Dali.

In frontal breadth, Salkhit at $98.06 \mathrm{~mm}$ is greater than the range of the Zhoukoudian sample (X, XI, XII, V), from 85.7 to $89 \mathrm{~mm}($ mean $=87.5 \mathrm{~mm})$, and smaller than Dali $(106.1 \mathrm{~mm})$ and the range of the Upper Cave sample (from 102 to $109.3 \mathrm{~mm}$ ). Salkhit is in between the values of the Zhoukoudian Locality 1 on one hand and the Upper Cave with Dali on the other hand (Fig. 6). Due to the small sample size, statistical test was not performed.

\section{INSERT Table 1 AND Fig. 6 ABOUT HERE}

\section{Supraorbitals}

Salkhit supraorbital region is complete, both externally and internally. An osseous bar extends across the frontal, like a supraorbital torus. The supraorbital region of the Salkhit skullcap plays a major role in giving an archaic appearance of the specimen; thus, the region is discussed in a separate section in this paper.

The supraorbital region projects from the frontal squama, with a demarcation between the squama and the torus, except for the glabellar region: from glabella the frontal squama continues smoothly without any depression superior to it. The demarcation that separates the supraorbital region from the frontal squama, however, is not a distinct sulcus, but rather a simple angulation (Fig. 5).

In Salkhit, the supraorbital tori on both sides are bridged by a glabellar torus rising above the nasal bridge. The glabellar torus is thinner in supero-inferior height than the supraorbital torus; there is a weak and shallow depression on glabella that marks the 
separation between the torus on two sides. This might be called a glabellar notch, although it is more a depression than a notch.

Seen from the front, the torus on both sides dips inferiorly at both medial and lateral ends, forming an M- or a seagull-shape for the supraorbital torus as a whole, contributed by the pinching of the glabellar torus. The supraorbital tori on both sides in Salkhit are bridged by a glabellar torus rising above the nasal bridge, which is also the case in the Zhoukoudian crania. The glabellar torus is thinner in supero-inferior height than the supraorbital torus. The M- or a seagull-shape for the supraorbital torus as a whole, contributed by the pinching of the glabellar torus (Fig. 3) found in Salkhit is also observed in some Zhoukoudian specimens (especially in Skull XII (L3)), UC 101, and Dali.

In Salkhit, the supraorbital torus on each side is demarcated by a faint groove that partially separates it into medial (superciliary) and lateral portions. Although the groove is palpable, it is not as clear as that which can be seen in the superciliary arch of modern humans, and thus cannot be called an incisura supraorbitalis.

The supraorbital morphology is modified due to the possible wound on the right supraorbitals (Fig. 5, arrow “A”). Slightly supero-lateral to the supraorbital foramen, there is a depression that may be attributable to a wound, near the supero-inferior midpoint and the media-lateral midpoint. It appears to be a blunt trauma limited to the external table and superficial diploë. There are no signs of infection or periosteal bone growth, which suggests that the wound was healed before death. On the left supraorbital region, there are two notches, near the midpoint toward the inferior edge (Fig. 5).

The medial portion of the supraorbitals is thicker than the lateral portion, a difference in the supero-inferior thickness between the medial and the lateral portions. There is no difference in the anterior projection between the medial and the lateral portions. The lateral portion of the torus thins out slightly, but the osseous bar continues to the most lateral point, as lateral as the frontozygomatic suture. The slight thinning of the lateral portion of the supraorbital region turns into a slight knob, a thickening of the supraorbital torus at the lateral ends where they meet the temporal lines. The thickening at the lateral ends of the supraorbitals is not comparable to that seen in the Zhoukoudian sample, which has a knobbed look. 
Is the structure in Salkhit a supraorbital torus or superciliary arch? On one hand, it can be described as a supraorbital torus: there is an osseous bar which continues without significant thinning, and the demarcation between the osseous bar and the frontal squama is clear. On the other hand, there is a weak but discernible incisura and the supraorbital groove, separating the torus into two components, medial and lateral. The supraorbital groove is weak. Since the lateral component maintains the osseous bar instead of a continuation without any change in topography from the frontal squama, it is not a superciliary arch as observed among extant humans. In superciliary arch of modern humans, the lateral portion does not have a thickening but a smooth continuation from the frontal squama that sharply turns into the superior orbital plate.

The continuous supraorbital torus gives Salkhit an archaic appearance. A closer comparison with the Zhoukoudian Locality 1 specimens, however, shows that Salkhit supraorbital region is not the same as the one seen in the Zhoukoudian Homo erectus sample. Salkhit and Zhoukoudian are similar in that they have thick and continuous lateral tori, but in Zhoukoudian the lateral portion is thicker and smoother, without any interruption in the surface of the torus. In Salkhit the lateral torus is continuous, but more gracile than the medial portion. In Zhoukoudian the supraorbital torus reaches maximum thickness toward the lateral end to form a 'knob' and then decreases abruptly into zygomatic processes.

In Salkhit, the separation between the torus and the frontal squama is most obvious in the medial portion of the torus, where there is a weak sulcus that does not continue across the midline. In contrast, in the Zhoukoudian sample supraorbital sulcus is an actual gutter that is dipping (as in Skull XII) or shallow and broad (as in Skull V), and is most pronounced where the supraorbital torus is the thickest.

In Salkhit and Zhoukoudian crania, the supraorbitals are different morphologically between the medial and the lateral halves. Zhoukoudian supraorbitals are thicker and farther projecting than that in Salkhit. In Zhoukoudian, the medial portion of the supraorbitals is slightly thinner than the lateral portion, and the lateral portion projects more anterior than in Salkhit.

The contrast between the medial and the lateral portions of the supraorbital region of Salkhit takes a different pattern in the Zhoukoudian sample. In the Zhoukoudian sample, 
medial and lateral portions are defined in morphology, but without a borderline defined by incisura. Both medial halves of Zhoukoudian supraorbitals are depressed, with less anterior projection than that of the lateral portion. The medial portion is laterally marked by supraorbital process (most prominent in Skull X), which is a tubercle. Weidenreich notes that the position of the depression corresponds to that of the incisura supraorbitalis in modern humans (Weidenreich, 1943:29). Supraorbital foramen is absent in Zhoukoudian. Notably, a double-notch is in the location of the supraorbital process in Zhoukoudian Skull XII.

Dali has a continuous supraorbital torus as is also seen in Salkhit, but the supraorbital torus in Dali is much thicker than that in Salkhit. In comparison with the three specimens in Zhoukoudian Upper Cave, two specimens, UC 102 and UC 103, do not show the continuous supraorbital torus seen in Salkhit. The supraorbital region in UC 102 and UC 103 is appropriately referred to as superciliary arch, rather than supraorbital torus. However, UC 101 shows a surprising similarity with Salkhit in many aspects.

In both Salkhit and UC 101, the supraorbital bar continues throughout the supraorbtial region; the medial portions are thicker than the lateral portions; the supraorbital torus thickens at the lateral end, resulting in a slightly knobbed look. There is a weak but discernible groove that separates the torus into two components, medial and lateral. In Salkhit, the medial and the lateral portions of the left supraorbital are demarcated by a faint groove, which is weaker than is observed in UC 101; it is almost an uninterrupted continuation of a torus on the right side, but it cannot be ascertained due to a possible distortion from the healed wound.

\section{Parietals}

Neither of the Salkhit parietal bones is complete. Greater proportion is preserved on the right parietal than on the left. Coronal suture can be seen in the medial portion; squama portion is not preserved, and that is where the coronal suture ends. On the right parietal, the maximum distance from sagittal suture is $77 \mathrm{~mm}$ (at the level of $50 \mathrm{~mm}$ posterior from bregma), and the maximum distance from coronal suture is $90 \mathrm{~mm}$ (at the level of $40 \mathrm{~mm}$ lateral from bregma). On the left parietal, the maximum distance from the sagittal suture is $62 \mathrm{~mm}$ (near the level of bregma), and the maximum distance from the 
coronal suture is $60 \mathrm{~mm}$ (on the sagittal suture). Only a part of the sagittal suture is preserved, and no other sutures (neither lambdoidal nor temporal sutures) are preserved. Toward the posterior end of the sagittal suture, the suture slightly bends to the right, and it looks like there is a superior fragment of an extrasutural bone. Presence of an extrasutural bone in the occiput is not unusual among Asian fossil record: for example, Salawusu (Ordos) (Wolpoff, 1999). However, it cannot be verified in Salkhit because the bone is broken off.

On the internal side, sagittal sinus is obliterated and cannot be discerned. Meningeal grooves on the left side are deeper than those on the right side (Fig. 3). The grooves for the medial meningeal arteries differ by side, in both the depth of the grooves as well as the pattern of branches. This suggests a bilaterality in the brain, which is reported to have appeared as early as Middle Pleistocene (Frayer et al., 2011).

There is no keel on the sagittal suture of Salkhit (Fig. 5), in contrast to Zhoukoudian specimens. On the right parietal, parietal boss is weakly discernible (Fig. 2). Temporal lines are weak, and it is unknown whether there is an angular torus because that portion is broken off. Because of the incomplete preservation of the parietals, metric comparison regarding overall size and curvature cannot be made.

The parietals form a low ridge posterior to bregma, and the two ridges form a narrow groove on the midsagittal plane (Fig. 2). These ridges diverge following the superior edge of the parietals, and the groove widens into a flat plane between the two weak ridges. Although only the ridge on the right side remains as the corresponding portion of the left parietal is broken off, the flattening can be observed.

Salkhit and UC 101 share a morphological feature seen in the parietals. On each side of the sagittal suture in Salkhit, there is a raised ridge that runs parallel to the sagittal suture, and the ridges follow the suture, diverging as they swerve posterior and inferior. This feature is seen in ZKD XII and UC 101, not present in Dali, and also present in European Late Pleistocene specimens such as Mladeč 5 (Frayer et al., 2006).

\section{Nasals}

In Salkhit, nasofrontal suture and frontomaxillary sutures form a continuous, horizontal course, similar to the case in Zhoukoudian Skull XII. In Skull XII, however, 
nasal bones are broad, with no difference between the upper breadth and the middle breadth, while in Salkhit, there is a contraction in breadth leading to a pinched, hourglass shape, and the minimal nasal breadth occurs inferior to the nasofrontal suture (Fig. 5).

There is one characteristic shared between Dali and Salkhit: the median margins of the Salkhit nasal bones rise to a sharp ridge along the internasal suture (Fig. 1 in $\mathrm{Wu}$ and Athreya, 2013) (Fig. 5, arrow "B"). Salkhit has a low nasal angle (height of the saddle made from two nasals) similar to that in Dali; Upper Cave specimens have higher nasal angle than either Salkhit or Dali.

\section{Discussion}

Although it long has been observed that archaic and modern features appear together in a mosaic within a single specimen, it is still the case when a fossil specimen is found without a clear date, an archaic or a robust look provides the basis upon which an assessment of an archaic species is made. The results of this paper provide another support that archaic features do not necessarily mark for the specimen to be of an archaic time. An archaic morphology may be an indication of an archaic ancestry, rather than an archaic time period.

Morphological comparison of Salkhit with other relevant specimens from Middle and Late Pleistocene northeast Asia suggests complex trajectories of different traits. Some traits are found consistently throughout. For example, sagittal keel is found in Asian specimens throughout Middle and Late Pleistocene. In addition to Salkhit, Dali, Zhoukoudian Locality 1 and Upper Cave, it is also found in Ziyang (Wolpoff, 1999).

The recent discovery of the genetic affinity between Sima de los Huesos and Denisovans (Meyer et al., 2014) adds to the body of evidence showing a persistent gene flow on different levels, within regions as well as between different regions. The complex pattern of differences, similarities, and intermediateness of various features lends support to a genetic continuity over time within that region, and is not compatible with a new species with morphological discontinuity.

A parallel example can be found in Ceprano, of which the initial date of 1 Ma was compatible with its archaic features (Manzi, 2004); however, its date is now considered to be half as old, $460 \mathrm{ka}$ (Muttoni et al., 2009), which puts the archaic features of 
Ceprano in a new light (Dennell et al., 2011). Ceprano is a member of a population that exhibits archaic features due to ancestry, and not because of an archaic date.

The morphology of Salkhit supraorbital region can be described as an intermediate between a supraorbital torus and a superciliary arch. It should be borne in mind that whether it is a supraorbital torus or superciliary arch is somewhat irrelevant in the investigation into affinity: the mere presence of torus does not define Salkhit to be an archaic specimen. A supraorbital torus is not exceptional nor unusual to be found among extant, recent humans, such as Mladeč (Frayer et al., 2006), Willandra Lake Hominid 50 and several from the Coobool Creek sample (Thorne and Wolpoff, 1981) being only a few of many examples. M-shaped supraorbitals are also found in specimens from Middle and Late Pleistocene, and also in Australians as recent as WLH 50 (Durband and Westaway, 2013). Considering the recent discovery of Denisovan genetic signal in southeast Asia while almost absent in northeast Asia (Reich et al., 2010, 2011; Skoglund and Jakobsson, 2011), the shared similarity between Salkhit and the recent Australians points toward a future research.

The "archaic" traits, so termed because they are found among Homo erectus specimens, are sometimes regionally predominant traits that persist throughout time, rather than time-markers for an archaic population. That a specimen such as Salkhit shows such a trait is not supportive of its antiquity; rather, it is compatible with its regional provenience.

Salkhit is similar to the Zhoukoudian Homo erectus, in ways that similarities are shared between Zhoukoudian Locality 1, Dali, and Upper Cave. These traits persist through time, and may be regionally predominant features. Such features are not unique to a region, but are found in high frequency in a region (Rosenberg and $\mathrm{Wu}, 2013$ ).

Salkhit is different from the Zhoukoudian Homo erectus sample in the same ways modern humans are different from Homo erectus, namely in the expansion of brain size and gracilization. Metric variables suggest a trend with a direction. While frontal length measurements do not change, as all specimens show values within the range defined by the Zhoukoudian Locality 1 sample, there is a distinct pattern in the frontal breadth measurements. Salkhit is in-between the Zhoukoudian Locality 1 and the Upper Cave specimens, suggesting an expansion in frontal breadth. This encephalization trend reflects 
what is found throughout Pleistocene, although the debate is not settled as to whether there was a punctuated or a gradual pattern of increase in cranial capacity (Lee and Wolpoff, 2003; Rightmire, 1981, 2004, 2013; Wolpoff, 1984). A corollary to that observation is that Salkhit has less postorbital constriction than the Zhoukoudian sample. The timing of cranial increase in frontal breadth is compatible with gracilization and encephalization, the two trends that are observed globally throughout Late Pleistocene human evolution (Wolpoff, 1999).

If the date mentioned in the magazine interview (Crooson, 2010), $27 \mathrm{ka}$, is substantiated, the observations made in this study are compatible with that date. Kaifu and Fujita (2012) suspect that the skullcap is a modern human, based on the suggested recent date.

Although Salkhit may not look like a member of the Zhoukoudian sample, it is still possible that Salkhit is a Middle Pleistocene specimen. This has particular relevance as questions arise whether Zhoukoudian is representative of Middle Pleistocene Asian Homo erectus: Antón argues that Zhoukoudian is an exception rather than a rule for Asian Homo erectus (Antón, 2003). The heterogeneity within the Chinese Homo erectus sample has been noted by several authors (Baab, 2008, 2010; Kidder and Durband, 2004). Considering that more research is showing early Homo to be more variable than was thought before (Lordkipanidze et al., 2013; Van Arsdale and Wolpoff, 2012), a wider range of specimens are necessary to provide a comparative perspective.

Results of this paper are not compatible with the null hypothesis that Salkhit is like a member of the Zhoukoudian Homo erectus sample. The features that Salkhit shares with the Zhoukoudian Homo erectus sample also are shared with later specimens from the region, Zhokoudian Upper Cave sample. Salkhit is different from the Zhoukoudian specimens in the same ways that later humans from Late Pleistocene are different from the Zhoukoudian Homo erectus specimens. On the basis of metrics, Salkhit is intermediate between the Locality 1 and the Upper Cave specimens. These differences reflect gracilization and encephalization. It is concluded that the archaic features in Salkhit are due to its archaic ancestry, rather than to its membership in an archaic population. Results of this study are compatible with the idea that archaic features are not 
necessarily temporal markers; rather, they can be regionally continuous features that undergo evolutionary changes.

\section{Acknowledgements}

My heartfelt gratitude to Yves Coppens (Centre National de Recherche Scientifique), Damdinsuren Tseveendorj (Mongolian Academy of Sciences), Milford Wolpoff (Univeristy of Michigan), and Seonbok Yi (Seoul National University) for their generous support. Robin Dennell and Bob Eckhardt helped strengthening this paper. This study was supported by University of California at Riverside, National Geographic Society, and National Science Foundation.

\section{References}

Antón, S.C., 2003. Natural history of Homo erectus. Yrbk Phys. Anthropol. 122, 126170.

Ao, H., Dekkers, M.J., Wei, Q., Qiang, X., Xiao, G., 2013. New evidence for early presence of hominids in North China. Scientific Reports 3, Article number 2403.

Baab, K.L., 2008. The taxonomic implications of cranial shape variation in Homo erectus. J. Hum. Evol. 54, 827-847.

Baab, K.L., 2010. Cranial shape in Asian Homo erectus: Geographic, anagenetic, and size-related variation. In: Norton, C.J., Braun, D.R. (Eds.), Asian Paleoanthropology. Springer, Netherlands, pp. 57-79.

Bae, C.J., 2010. The late Middle Pleistocene hominin fossil record of eastern Asia: Synthesis and review. Am. J. Phys. Anthropol. 143, 75-93.

Boeskorov, G.G., 2012. Some specific morphological and ecological features of the fossil woolly rhinoceros (Coelodonta antiquitatis Blumenbach 1799). Biol. Bull. Russ. Acad. Sci. 39, 692-707.

Buikstra, J.E., Ubelaker, D.H., (Eds.), 1994. Standards for Data Collection from Human Skeletal Remains. Proceedings of a Seminar at the Field Museum of Natural History. Arkansas Archeological Survey, Fayetteville, Arkansas. 
Coppens, Y., Tseveendorj, D., Demeter, F., Turbat, T., Giscard, P.-H., 2008. Discovery of an archaic Homo sapiens skullcap in Northeast Mongolia. Comptes Rendus Palevol. 7, 51-60.

Crooson, D.L., 2010. Vieus d'environ 20,000 ans l'homme de Salkhit a parlé. National Geographic 2010, 49-57.

Dennell, R., 2003. Dispersal and colonisation, long and short chronologies: how continuous is the Early Pleistocene record for hominids outside East Africa? J. Hum. Evol. 45, 421-440.

Dennell, R.W., Martinón-Torres, M., Bermúdez de Castro, J.M., 2011. Hominin variability, climatic instability and population demography in Middle Pleistocene Europe. Quat. Sci. Rev. 30, 1511-1524.

Derevianko, A.P., 2011. The origin of anatomically modern humans and their behavior in Africa and Eurasia. Archaeol. Ethnol. Anthropol. Eurasia 39, 2-31.

Durband, A.C., Westaway, M.C., 2013. Perspectives on the origins of modern Australians. In: Smith, F.H., Ahern, J.C.M. (Eds.), Origins of Modern Humans: Biology Reconsidered, $2^{\text {nd }}$ ed. Wiley, New York, pp. 123-150.

Frayer, D.W., Jelínek, J., Oliva, M., Wolpoff, M.H., 2006. Aurignacian male crania, jaws, and teeth from the Mladeč Caves, Moravia, Czech Republic. In: TeschlerNicola, M. (Ed.), Early Modern Humans at the Moravian Gate: The Mladeč Caves and their Remains. Springer, Wien, pp. 185-272.

Frayer, D.W., Lozano, M., Bermúdez de Castro, J.M., Carbonell, E., Arsuaga, J.L., Radovčić, J., Fiore, I., Bondioli, L., 2011. More than 500,000 years of righthandedness in Europe. Laterality: Asymmetries of Body, Brain and Cognition 17, 5169.

Hershkovitz, I., Latimer, B.M., Dutour, O., Jellema, L.M., Wish-Baratz, S., Rothschild, B.M., 1997. Why do we fail in aging the skull from the sagittal suture? Am. J. Phys. Anthropol. 103, 393-399.

Kaifu, Y., Fujita, M., 2012. Fossil record of early modern humans in East Asia. Quat. Int. 248, 2-11.

Kidder, J.H., Durband, A.C., 2004. A re-evaluation of the metric diversity within Homo erectus. J. Hum. Evol. 46, 297-313. 
Lee, S.-H., Wolpoff, M.H., 2003. The pattern of Pleistocene human brain size evolution. Paleobiology 29, 185-195.

Lordkipanidze, D., Ponce de León, M.S., Margvelashvili, A., Rak, Y., Rightmire, G.P., Vekua, A., Zollikofer, C.P.E., 2013. A complete skull from Dmanisi, Georgia, and the evolutionary biology of early Homo. Science 342, 326-331.

Manzi, G., 2004. Human evolution at the Matuyama-Brunhes boundary. Evol. Anthropol. $13,11-24$.

Marsh, H.E., 2013. Beyond Thick versus Thin: Mapping Cranial Vault Thickness Patterns in Recent Homo sapiens, Anthropology. University of Iowa, Iowa City, Iowa. Martin, R., Saller, K., 1957. Lehrbuch der Anthropologie. Gustav Fischer Verlag, Stuttgart.

Meindl, R.S., Lovejoy, C.O., 1985. Ectocranial suture closure: A revised method for the determination of skeletal age at death based on the lateral-anterior sutures. Am. J. Phys. Anthropol. 68, 57-66.

Meyer, M., Fu, Q., Aximu-Petri, A., Glocke, I., Nickel, B., Arsuaga, J.-L., Martinez, I., Gracia, A., de Castro, J.M.B., Carbonell, E., Pääbo, S., 2014. A mitochondrial genome sequence of a hominin from Sima de los Huesos. Nature 505, 403-406.

Muttoni, G., Scardia, G., Kent, D.V., Swisher, C.C., Manzi, G., 2009. Pleistocene magnetochronology of early hominin sites at Ceprano and Fontana Ranuccio, Italy. Earth and Planetary Science Letters 286, 255-268.

Pappu, S., Gunnell, Y., Akhilesh, K., Braucher, R.G., Taieb, M., Demory, F.B., Thouveny, N., 2011. Early Pleistocene presence of Acheulian hominins in South India. Science 331, 1596-1599.

Reich, D., Green, R.E., Kircher, M., Krause, J., Patterson, N., Durand, E.Y., Viola, B., Briggs, A.W., Stenzel, U., Johnson, P.L.F., Maricic, T., Good, J.M., Marques-Bonet, T., Alkan, C., Fu, Q., Mallick, S., Li, H., Meyer, M., Eichler, E.E., Stoneking, M., Richards, M., Talamo, S., Shunkov, M.V., Derevianko, A.P., Hublin, J.-J., Kelso, J., Slatkin, M., Pääbo, S., 2010. Genetic history of an archaic hominin group from Denisova Cave in Siberia. Nature 468, 1053-1060.

Reich, D., Patterson, N., Kircher, M., Delfin, F., Nandineni, Madhusudan R., Pugach, I., Ko, Albert M.-S., Ko, Y.-C., Jinam, Timothy A., Phipps, Maude E., Saitou, N., 
Wollstein, A., Kayser, M., Pääbo, S., Stoneking, M., 2011. Denisova admixture and the first modern human dispersals into Southeast Asia and Oceania. Am. J. Hum. Genet. 89, 516-528.

Rightmire, G.P., 1981. Patterns in the evolution of Homo erectus. Paleobiology 7, 241246.

Rightmire, G.P., 2004. Brain size and encephalization in early to Mid-Pleistocene Homo. Am. J. Phys. Anthropol. 124, 109-123.

Rightmire, G.P., 2013. Homo erectus and Middle Pleistocene hominins: Brain size, skull form, and species recognition. J. Hum. Evol. 65, 223-252.

Rosenberg, K.R., Wu, X., 2013. A river runs through it: modern human origins in East Asia. In: Smith, F.H., Ahern, J.C.M. (Eds.), Origins of Modern Humans: Biology Reconsidered, $2^{\text {nd }}$ ed. Wiley, New York, pp. 89-121.

Skoglund, P., Jakobsson, M., 2011. Archaic human ancestry in East Asia. Proc. Natl Acad. Sci. U.S.A. 108, 18301-18306.

Thorne, A.G., Wolpoff, M.H., 1981. Regional continuity in Australasian Pleistocene hominid evolution. Am. J. Phys. Anthropol. 55, 337-349.

Tseveendorj, D., Batbold, N., Amgalantogs, T., 2006. Mongolanthropus was discovered in Mongolia. Studia Archeologica Instituti Archaeologici Academiae Scientiarum Mongolicae 23, 5-10 [in Mongolian].

Van Arsdale, A.P., Wolpoff, M.H., 2012. A single lineage in early Pleistocene Homo: Size variation continuity in early Pleistocene Homo crania from East Africa and Georgia. Evolution 67, 841-850.

Weidenreich, F., 1943. The skull of Sinanthropus pekinensis: A comparative study of a primitive hominid skull. Palaeontologia Sinica, New Series D 10.

Weidenreich, F., 1951. Morphology of Solo man. Anthropological Papers of the American Museum of Natural History 43, 205-290.

Weiss, K.M., 1972. On the systematic bias in skeletal sexing. Am. J. Phys. Anthropol. 37, 239-249.

Wolpoff, M.H., 1984. Evolution in Homo erectus: the question of stasis. Paleobiology 10, $389-406$.

Wolpoff, M.H., 1999. Paleoanthropology, $2^{\text {nd }}$ ed. McGraw-Hill, New York. 
Wu, X., Athreya, S., 2013. A description of the geological context, discrete traits, and linear morphometrics of the Middle Pleistocene hominin from Dali, Shaanxi Province, China. Am. J. Phys. Anthropol. 150, 141-157.

Zhu, R., An, Z., Potts, R., Hoffman, K.A., 2003. Magnetostratigraphic dating of early humans in China. Earth-Science Reviews 61, 341-359.

Zhu, R.X., Hoffman, K.A., Potts, R., Deng, C.L., Pan, Y.X., Guo, B., Shi, C.D., Guo, Z.T., Yuan, B.Y., Hou, Y.M., Huang, W.W., 2001. Earliest presence of humans in northeast Asia. Nature 413, 413-417.

Zhu, R.X., Potts, R., Pan, Y.X., Yao, H.T., L, L.Q., Zhao, X., Gao, X., Chen, L.W., Gao, F., Deng, C.L., 2008. Early evidence of the genus Homo in East Asia. J. Hum. Evol. 55, 1075-1085.

Zhu, R.X., Potts, R., Xie, F., Hoffman, K.A., Deng, C.L., Shi, C.D., Pan, Y.X., Wang, H.Q., Shi, R.P., Wang, Y.C., Shi, G.H., Wu, N.Q., 2004. New evidence on the earliest human presence at high northern latitudes in northeast Asia. Nature 431, 559-562. 


\section{Legends to Figures}

Fig. 1. Map of northeast Asia showing localities mentioned in the text, modified from Coppens et al. (2008). Xujiayao site represents the Paleolithic sites in the Nihewan Basin.

Fig. 2. Superior view of the Salkhit skullcap. Anterior is towards the top of the photo. Osteometric points are shown $(\mathrm{ft}=$ frontotemporale; $\mathrm{gl}=$ glabella $)$.

Fig. 3. Inferior view of the Salkhit skullcap. Anterior is towards the top of the photo. Arrow shows a piece that is missing from the posterior tip, probably extracted for analysis.

Fig. 4. Orientation is estimated based on the supraorbital and the nasal region, and closely matches that in the original report (Tseveendorj et al., 2006). Right side is shown. Osteometric points are shown (br=bregma; na=nasion).

Fig. 5. Anterior view of the Salkhit skullcap. Arrow "A" points to the possible healed wound. Arrow "B" points to the internasal ridge.

Fig. 6. Scatterplot of frontal length (chord) versus frontal breadth. Salkhit is inbetween the Zhoukoudian Locality 1 specimens and the Zhoukoudian Upper Cave specimens. 
Table 1. Frontal metric data. Osteometric points $\mathrm{ft}=$ frontotemporale $; \mathrm{gl}=$ glabella $; \mathrm{br}=$ bregma. M9 refers to the osteometric point number 9 using the Martin numbering system (Martin and Saller, 1957).

\begin{tabular}{|l|r|r|r|r|}
\hline & ft-ft (M9) & gl-br arc & gl-br chord & curvature \\
\hline Salkhit & 98.06 & 117.0 & 107.22 & 109.12 \\
\hline ZKD10 & 89.00 & 120.5 & 114.70 & 105.06 \\
\hline ZKD11 & 85.70 & 114.0 & 105.40 & 108.16 \\
\hline ZKD12 & 87.90 & 110.0 & 107.00 & 102.80 \\
\hline ZKD5 & 87.40 & 122.0 & 116.10 & 105.08 \\
\hline ZKD2 & 84.00 & 115.0 & 111.50 & 103.14 \\
\hline Dali & 106.10 & 127.0 & 114.75 & 110.68 \\
\hline UC101 & 109.30 & 117.5 & 108.80 & 108.00 \\
\hline UC102 & 104.00 & 119.5 & 111.00 & 107.66 \\
\hline UC103 & 102.00 & 113.0 & 104.00 & 108.65 \\
\hline
\end{tabular}

(unit: $\mathrm{mm}$ ) 




Fig. 1 


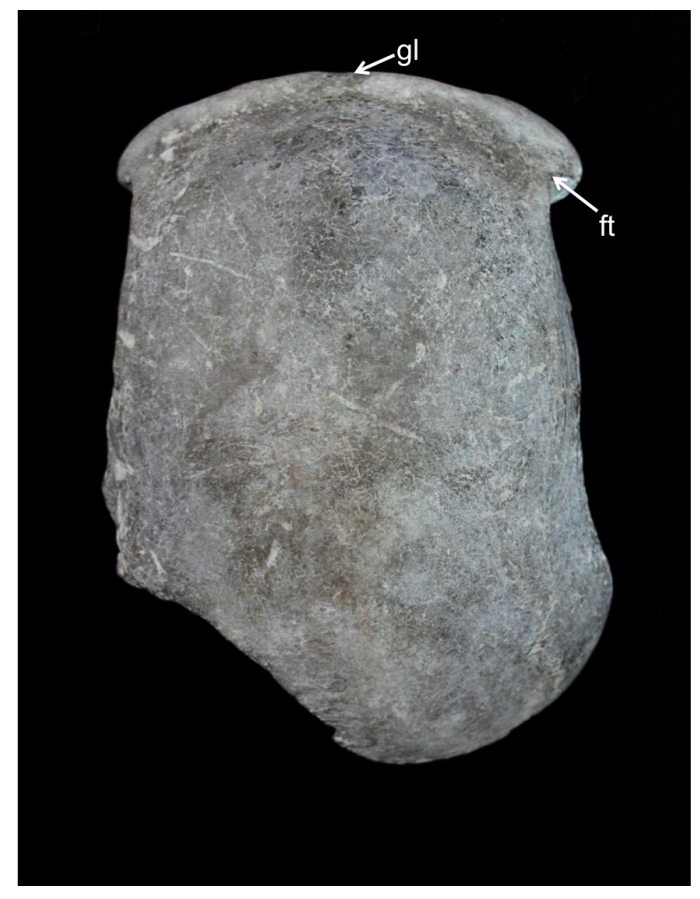

Fig. 2. 


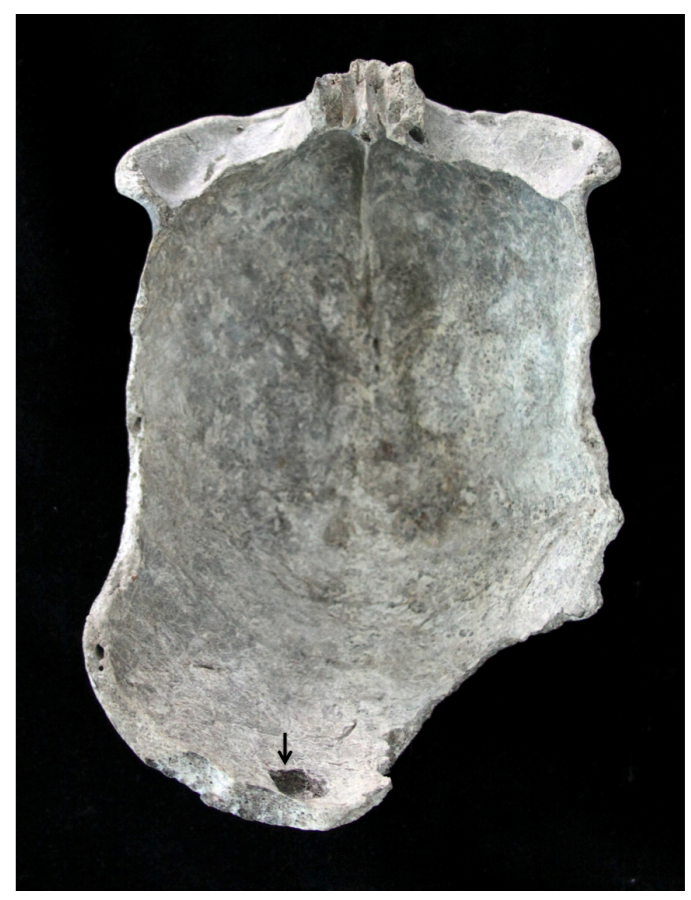

Fig. 3. 


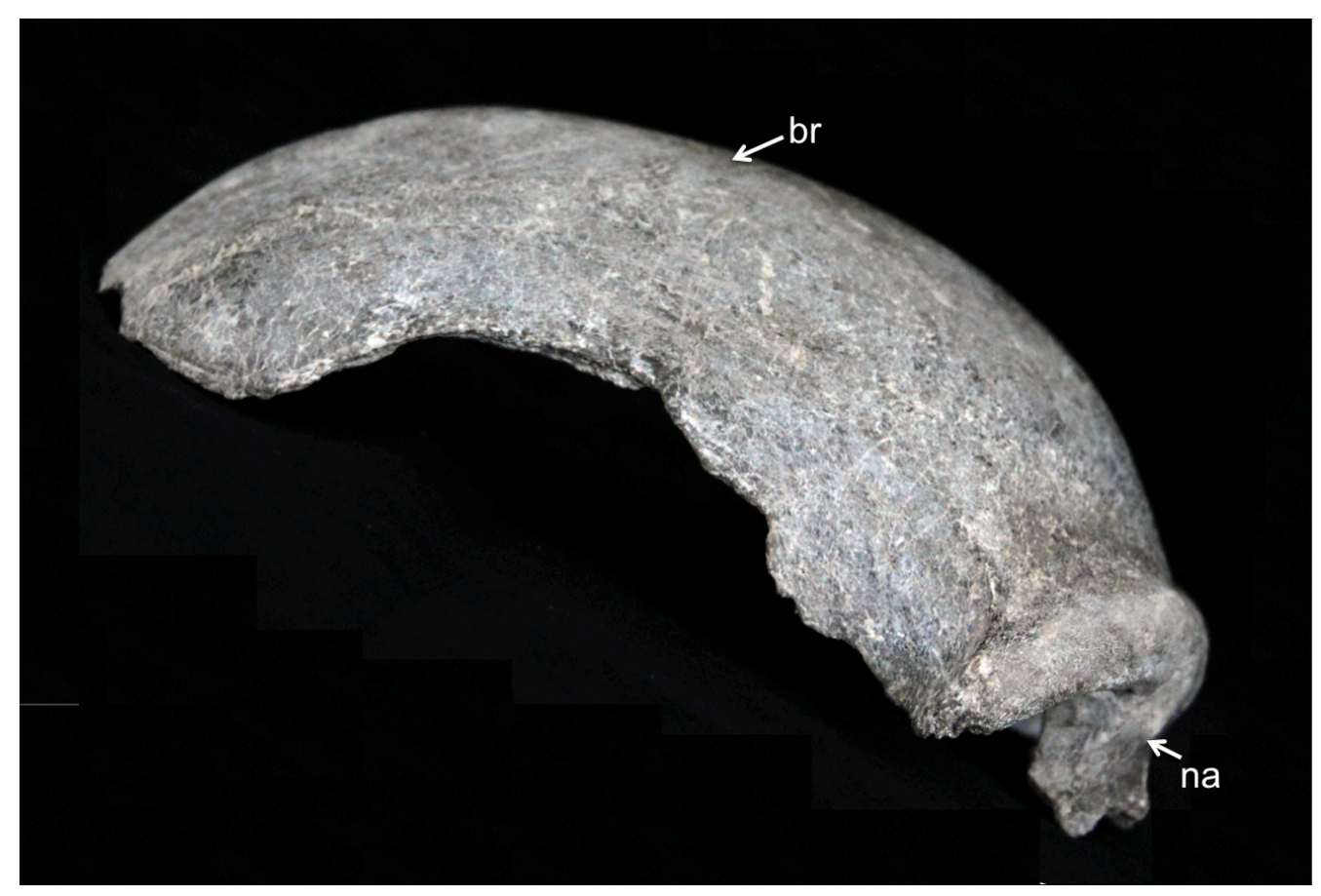

Fig. 4. 


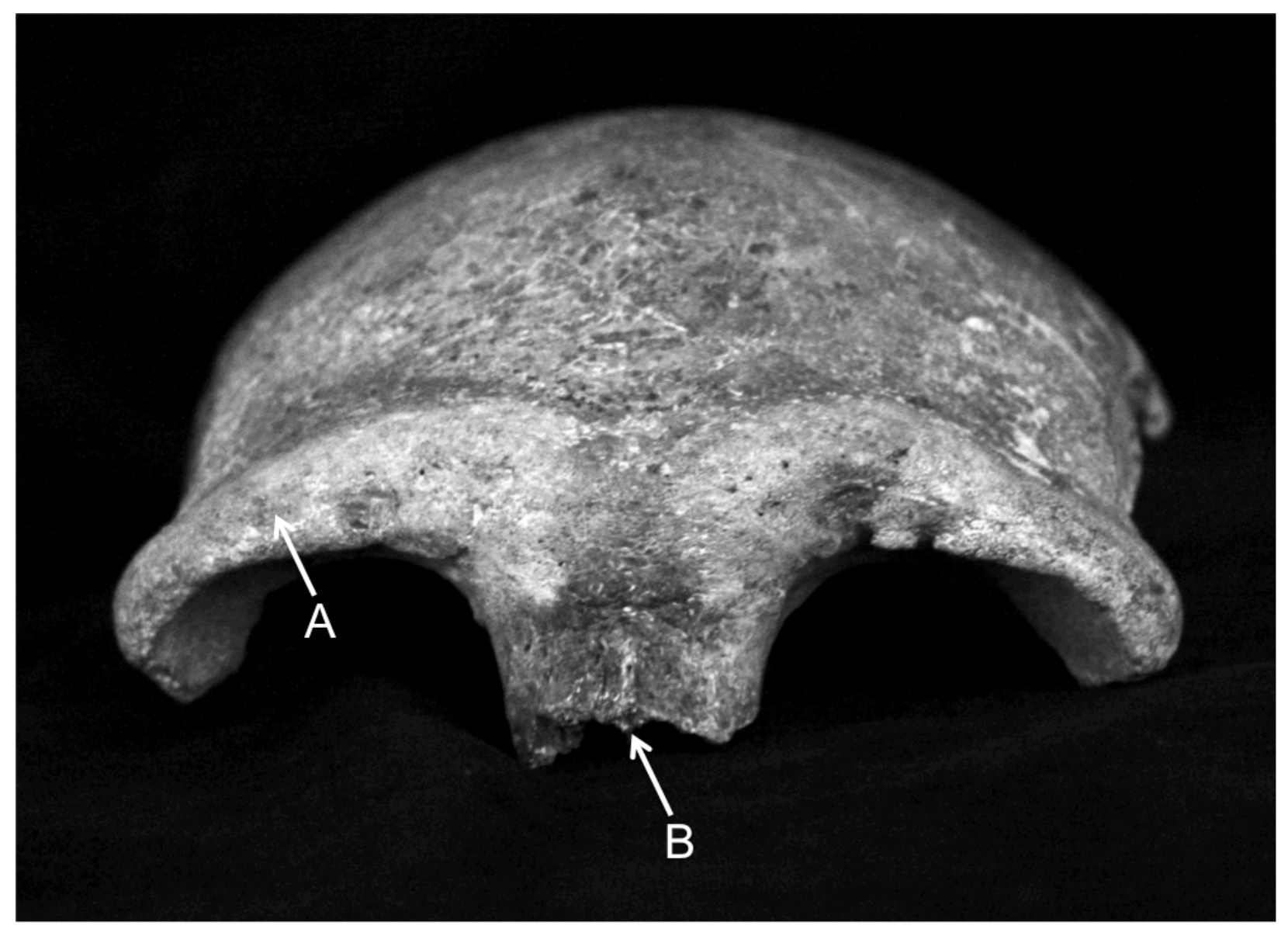

Fig. 5. 


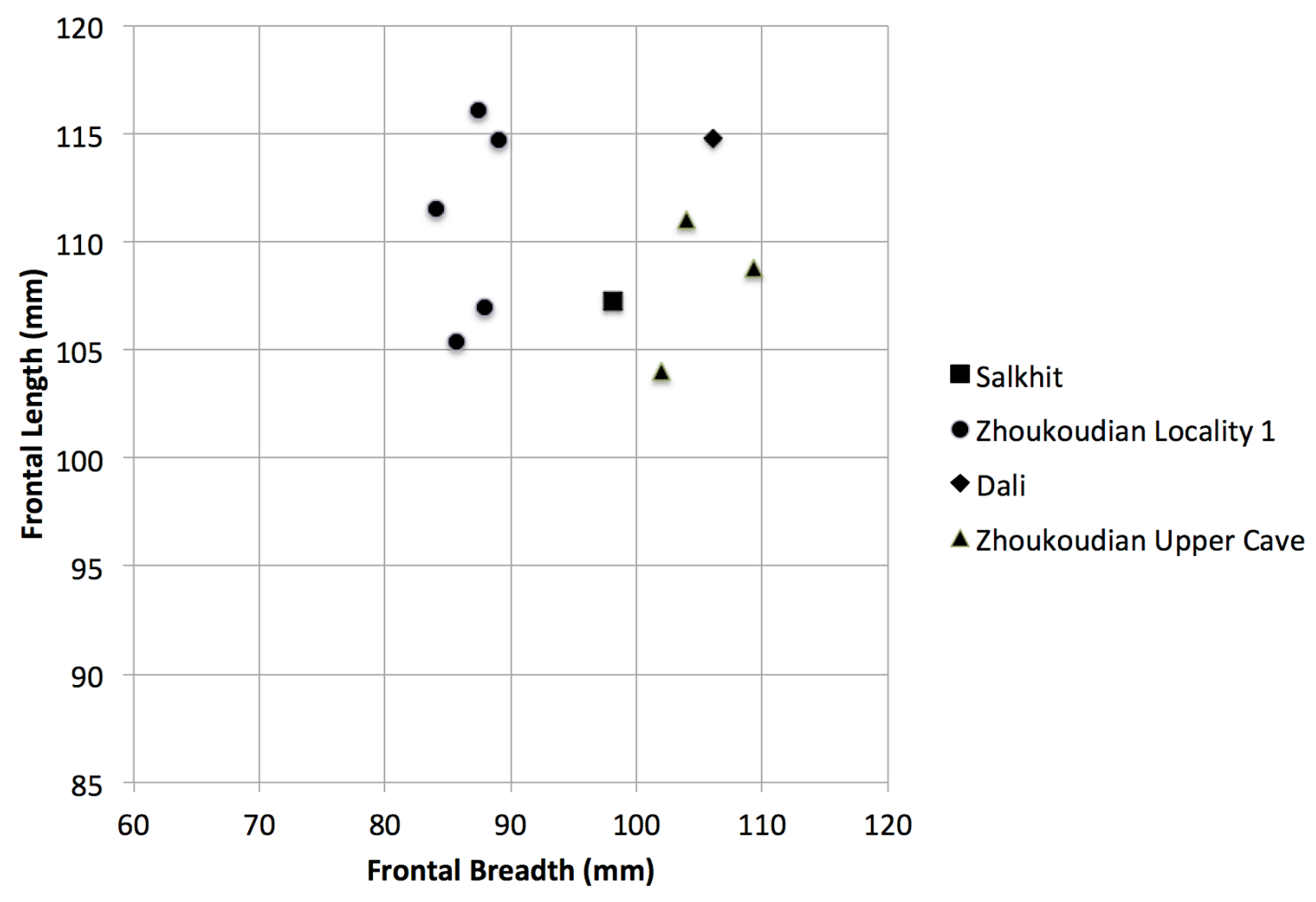

Fig. 6. 